Aim of the study: In this pilot study lipopolysaccharide-binding protein (LBP) levels were assessed as a possible risk factor for development of systemic inflammatory response syndrome (SIRS) and infectious and inflammatory complications in colorectal cancer (CRC) patients after surgery. Material and methods: For LBP determination venous blood was taken 1 hour before the surgery and 72 hours after it. All patients were stratified by the presence or absence of acute bowel obstruction (ABO), SIRS and complications.

Results: 36 patients with CRC participated in the study. The LBP level before surgery was $879.8 \pm 221.8 \mathrm{ng} / \mathrm{ml}$ (interquartile range (IQR) 749.31028.8); on the $3^{\text {rd }}$ day it was $766.5 \pm$ $159.4 \mathrm{ng} / \mathrm{ml}$ (IQR 669.5-847.6), which was a statistically significant decrease $(p=0.004)$. A decrease in LBP level by more than $280 \mathrm{ng} / \mathrm{ml}$ increases the probability of SIRS and complications in operated CRC patients (OR 6.6, $95 \% \mathrm{Cl}: 1.1-40.9$ and OR $12.0,95 \% \mathrm{Cl}$ 1.8-80.4, respectively). In patients with $A B O$ in the presence of SIRS, the LBP value decreased more than in those without SIRS ( $p=0.046)$.

Conclusions: This study demonstrated that the LBP level in the operated CRC patients tends to decrease on the $3^{\text {rd }}$ day after surgery. A bigger decrease in LBP level increases the probability of SIRS and postoperative infectious and inflammatory complications. Therefore, further studies with larger numbers of patients are required.

Key words: lipopolysaccharide-binding protein, colorectal cancer, bowel obstruction, bacterial translocation, SIRS, complications.

Contemp Oncol (Pozn) 2021; 25 (3): 198-203 DOI: https://doi.org/10.5114/wo.2021.110051

\section{Lipopolysaccharide-binding protein as a risk factor for development of infectious and inflammatory postsurgical complications in colorectal cancer patients}

\author{
Yermek Turgunov ${ }^{1}$, Alina Ogizbayeva ${ }^{1}$, Lyudmila Akhmaltdinova², \\ Kayrat Shakeyev ${ }^{1}$
}

'Department of Surgical Diseases, NJSC “Karaganda Medical University”, Karaganda, Kazakhstan

2Collective Use Laboratory of the Research Center, NJSC "Karaganda Medical University", Karaganda, Kazakhstan

\section{Introduction}

Colorectal cancer (CRC) is one of the major public health problems worldwide. It is one of the most common malignant diseases and one of the most important causes of cancer-related mortality (4th place in the world) [1]. Over $66 \%$ of CRC patients are urgently admitted due to complications [2]. Acute bowel obstruction (ABO) is the most common complication, which accounts for $80-85 \%$ of emergency surgical admissions in these patients [3]. There are still high rates of postoperative infectious and inflammatory complications (46-50\% of cases) and mortality (up to $32 \%$ of cases) [4, 5].

These days, bacterial translocation (BT) takes one of the main roles in the development of infectious and inflammatory complications. Bacterial translocation is the invasion of intestinal bacteria and bacterial endotoxins through the intestinal mucosa into the systemic circulation and normally sterile tissues and internal organs afterwards [6]. Thus, for the early diagnosis of such complications, as well as the detection of BT, some appropriate markers in the blood serum are to be determined. One such marker is lipopolysaccharide-binding protein (LBP).

Lipopolysaccharide-binding protein is an acute-phase protein, which is responsible for transporting endotoxin (lipopolysaccharide - LPS) to immune effector cells (macrophages, monocytes, and neutrophils). Also, LBP binds to other bacterial products such as glycolipids and lipopeptides [7]. After binding to CD14 on the surfaces of immune effector cells, the LBP/LPS complex activates the inflammatory signaling pathway $[8,9]$. The production and release of inflammatory mediators can result in the occurrence of systemic inflammatory response syndrome (SIRS) [10].

Today, LBP research in CRC patients is of interest to scientists around the world. The research is not only focused on inflammatory response indicators, but also on risk factors for development of CRC. In the study conducted by Chen et al., the functional G allele in the LBP rs2232596 single nucleotide polymorphism showed a significant association with high risk of CRC [11]. On the other hand, Citronberg's study did not find an association between LBP and CRC, or any association with body mass index (BMI), saturated fat intake, dietary fat intake, cancer site, or cancer condition [12]. However, in Cybulska-Stopa's study, a higher BMI is associated with a statistically significantly better prognosis in patients with CRC [13].

Currently, anti-inflammatory therapy is considered not only for the treatment of infectious-inflammatory complications, but also as part of antican- 
cer therapy. Therefore, numerous scientists are exploring the role of various inflammatory factors and their dependence on cancer staging. One study used the Human Circulation Biomarker panel, which included a large number of inflammatory markers: interleukin (IL)-6, IL-8, macrophage migration inhibition factor, fibroblast growth factor (FGF-2), stem cell factor (SCF), transforming growth factor (TGF), tumor necrosis factor (TNF), TNF apoptosis-inducing ligand (TRAIL). Only IL-6 demonstrated a substantial increase, but there was no dependence on CRC stage [14].

As for the study of LBP, any alterations in the intestinal mucosa in CRC patients contribute to the translocation of bacteria and their endotoxins into the systemic circulation [15]. Since LPS and bacterial endotoxins trigger the production of LBP, it can be a reliable biomarker for endotoxemia associated with barrier dysfunction and BT $[16,17]$. LBP concentrations in serum are suggested to be assessed as a valid marker of BT, SIRS and systemic infectious complications [18-21].

The aim of this pilot study is to analyze the dynamic changes in LBP level in blood serum and to assess it as a possible risk factor for the development of SIRS as well as infectious and inflammatory postsurgical complications in CRC patients.

\section{Material and methods}

Patients' records. The study was conducted from September 2020 to February 2021 in two hospitals in Karaganda, Kazakhstan (Multidisciplinary Hospital No. 1 and No. 3). This pilot study included 36 patients with CRC (15 males and 21 females aged 38-89 years). The median age was $65.7 \pm 12.4$ years (interquartile range (IQR) 60-75 years). By localization, sigmoid colon cancer prevailed in men (7 patients $-47 \%)$, sigmoid colon cancer (8 patients - 38\%) and colon cancer (7 patients - 33\%) in women. All patients' medical records are shown in Table 1. Patients under the age of 18, pregnant women, those having liver cirrhosis or HIV infection, and those who refused to participate were excluded. All patients underwent clinical, instrumental and laboratory research methods in hospitals in accordance with clinical protocol No. 60 "Acute bowel obstruction" issued by the Ministry of Health of the Republic of Kazakhstan. The clinical diagnosis was made after the surgery and on the basis of the obtained histological results. The presence of SIRS was assessed by the occurrence of at least two of the following criteria: fever $>38.0^{\circ} \mathrm{C}$ or hypothermia $\left\langle 36.0^{\circ} \mathrm{C}\right.$, leukocytosis $>12 \times 10^{9} / \mathrm{l}$ or leucopoenia $<4 \times 10^{9} /$, tachycardia $>90$ beats/minute, tachypnea $>20$ breaths/minute. Venous blood was taken 1 hour before the surgery and 72 hours after it (on the $3^{\text {rd }}$ day) to determine the LBP level. To compare the change in the LBP level on the $3^{\text {rd }}$ day, the patients were divided into two groups with either a decrease or an increase of LBP on the $3^{\text {rd }}$ day. To evaluate the association of LBP levels with the presence of $A B O$ and SIRS, all patients were stratified by the presence or absence of ABO, SIRS or no-SIRS.

\section{Blood collection}

Venous blood was sampled 1 hour before the surgery and on the $3^{\text {rd }}$ day after it. Venous blood was collected in
$5 \mathrm{ml}$ vacutainers with a coagulation activator and a serum gel separator. It was centrifuged for 20 minutes at 1000 x g, after which the gel completely separated the serum from the clot, forming a tight barrier. The obtained sample of freshly prepared serum was stored at $-20^{\circ} \mathrm{C}$ to $-80^{\circ} \mathrm{C}$ for up to 2 months, in order to avoid any loss of biological activity and contamination. No repeated freeze/thaw cycles were allowed.

\section{Lipopolysaccharide-binding protein determination}

ELISA Kit for LBP (Human) from Cloud-Clone Corp. was used to determine any presence of LBP. The analysis was performed according to the manufacturer's instructions for an ELISA EVOLIS robotic system from BioRad. The microplate provided in this kit was pre-coated with biotinconjugated antibodies specific for LBP. The standards and patient serum samples were added to appropriate wells of the microplate and incubated at $37^{\circ} \mathrm{C}$. Subsequently, some

Table 1. General medical records of the patients $(n=36)$

\begin{tabular}{|c|c|}
\hline Age & $65.7 \pm 12.4$ years (IQR 60-75 years) \\
\hline \multicolumn{2}{|l|}{ Gender } \\
\hline Male & $15(41.7 \%)$ \\
\hline Female & $21(58.3 \%)$ \\
\hline \multicolumn{2}{|l|}{ Cancer staging } \\
\hline । & $5(13.9 \%)$ \\
\hline$\|$ & $17(47.2 \%)$ \\
\hline III & $9(25.0 \%)$ \\
\hline IV & $5(13.9 \%)$ \\
\hline \multicolumn{2}{|l|}{ Tumor localization } \\
\hline Rectum & $5(13.9 \%)$ \\
\hline Rectosigmoid junction & $3(8.3 \%)$ \\
\hline Sigmoid colon & $15(41.7 \%)$ \\
\hline Colon & $10(27.8 \%)$ \\
\hline Cecum & $3(8.3 \%)$ \\
\hline \multicolumn{2}{|l|}{ ABO on admission } \\
\hline Absence & $23(63.9 \%)$ \\
\hline Presence & $13(36.1 \%)$ \\
\hline \multicolumn{2}{|l|}{ SIRS } \\
\hline Absence & $23(63.9 \%)$ \\
\hline Presence & $13(36.1 \%)$ \\
\hline \multicolumn{2}{|l|}{ Complications } \\
\hline Absence & $26(72.2 \%)$ \\
\hline Presence & $10(27.8 \%)$ \\
\hline Wound suppuration & 1 \\
\hline Anastomotic leak & 6 \\
\hline Abdominal abscesses & 5 \\
\hline Peritonitis & 5 \\
\hline Sepsis & 3 \\
\hline
\end{tabular}

SIRS - systemic inflammatory response syndrome, $A B O$ - acute bowel obstruction, $I Q R$ - interquartile range 
avidin conjugated with horseradish peroxidase was added to each well and incubated at $37^{\circ} \mathrm{C}$ once again. After addition of the TMB substrate solution, only those wells containing LBP changed color. These changes were measured spectrophotometrically at a wavelength of $450 \mathrm{~nm}$ $\pm 10 \mathrm{~nm}$. The LBP levels in the samples were then determined by comparing the absorbance of the samples with a standard calibration sample.

\section{Statistical analysis}

The number of the examined patients was calculated according to the recommendations for sample calculations for pilot studies [22]. The statistical analysis was carried out using STATISTICA v8.0 (StatSoft). The data are presented as mean (M), standard deviation (SD) and IQR. The Shapiro-Wilk test indicated that LBP values did not follow a normal distribution; consequently, non-parametric statistical tests were applied. The Wilcoxon nonparametric test was used to compare the LBP values before and after the surgery. The comparison between the two independent groups was performed using the Mann-Whitney $U$ test. To compare the decrease or the increase in LBP level on the $3^{\text {rd }}$ day, depending on the presence of SIRS and complications, the Fisher exact test was used. The significance level was set at $p<0.05$.

\section{Results}

Measurement of lipopolysaccharide-binding protein level in real-time mode

LBP levels were measured 1 hour before the surgery and 72 hours after it (on the $3^{\text {rd }}$ day). The value of LBP before the surgery was $879.8 \pm 221.8 \mathrm{ng} / \mathrm{ml}(\mathrm{IQR} 749.3-1028.8)$ and $766.5 \pm 159.4 \mathrm{ng} / \mathrm{ml}$ (IQR 669.5-847.6) on the $3^{\text {rd }}$ day, which was a statistically significant decrease $(p=0.004)$. In patients with $\mathrm{ABO}$, the $\mathrm{LBP}$ level before the surgery was $963.8 \pm 195.2 \mathrm{ng} / \mathrm{ml}$ (IQR 810.7-1044.1) and $808.8 \pm$ $208.4 \mathrm{ng} / \mathrm{ml}$ (IQR 644.9-1031.8) on the $3^{\text {rd }}$ day, which was also a statistically significant decrease $(p=0.023)$. In patients without $A B O$, no statistically significant difference was found. The LBP decreased in 28 patients on the $3^{\text {rd }}$ day, and only 8 patients had an increase in LBP level. 12 patients with $A B O$ and 16 without $A B O$ had a decrease in LBP level with only 1 patient with $A B O$ and 7 patients without $\mathrm{ABO}$ demonstrating an $\mathrm{LBP}$ increase. There was no statistically significant association between the change in LBP level on the $3^{\text {rd }}$ day and the presence of $\mathrm{ABO}(p=0.122)$.

There were no significant differences in gender or LBP levels either before the surgery or after it on the $3^{\text {rd }}$ day
( $p=0.76$ and $p=0.19$, respectively). There were 3 men (20\%) and 2 women (9\%) with stage I, 8 men (53\%) and 9 women (43\%) with stage II, 4 men (27\%) and 5 women (24\%) with stage III, 5 women (24\%) and no men with stage IV. Furthermore, there were no differences in the cancer stage and LBP levels before and after the surgery on the $3^{\text {rd }}$ day ( $p=0.49$ and $p=0.75$, respectively).

Association of lipopolysaccharide-binding protein with clinical presence of systemic inflammatory response syndrome

In no-SIRS patients $(n=23)$, the LBP level before the surgery was $871.9 \pm 205.6 \mathrm{ng} / \mathrm{ml}$ (IQR 724.7-976.6) and $791.5 \pm 156.1 \mathrm{ng} / \mathrm{ml}\left(\right.$ IQR 681.8-933.6) on the $3^{\text {rd }}$ day. In SIRS patients $(n=13)$, the LBP value before the surgery was $893.9 \pm 256.3 \mathrm{ng} / \mathrm{ml}($ IQR 786.1-1044.1) and $722.4 \pm$ $161.5 \mathrm{ng} / \mathrm{ml}$ (IQR 577.3-792.3) on the $3^{\text {rd }}$ day. It was also found that an LBP level decrease of more than $280 \mathrm{ng} / \mathrm{ml}$ increases the probability of SIRS (OR 6.6, 95\% CI: 1.1-40.9) (Table 2). In patients with $A B O$ in the presence of SIRS, the LBP value decreased more than in those without SIRS $(p=0.046)$. In 9 patients with SIRS and 19 patients without SIRS, the LBP level decreased on the $3^{\text {rd }}$ day, and only 2 patients with SIRS and 6 patients without SIRS had an increase in the LBP level. There was no significant association between the change in LBP level on the $3^{\text {rd }}$ day and the presence of SIRS $(p=0.382)$.

\section{Association of lipopolysaccharide-binding protein with development of postoperative infection and inflammatory complications}

In patients without postoperative complications, the LBP level before the surgery was $876.3 \pm 200.3 \mathrm{ng} / \mathrm{ml}($ IQR 767.7-976.6) and $783.2 \pm 155.5 \mathrm{ng} / \mathrm{ml}$ (IQR 681.8-866) on the $3^{\text {rd }}$ day. In patients with postoperative complications, the LBP value before the surgery was $887.8 \pm 275.4 \mathrm{ng} / \mathrm{ml}$ (IQR 730.9-111.7) and $728.6 \pm 169 \mathrm{ng} / \mathrm{ml}($ IQR 552.8-792.3) on the $3^{\text {rd }}$ day. In 8 patients with complications and 20 patients without them, the LBP level decreased on the $3^{\text {rd }}$ day. Two patients with complications and 6 patients without them had an increase in the LBP level. There was no significant association between the increase/decrease in LBP level on the $3^{\text {rd }}$ day and the presence of complications ( $p=0.532$ ). It was found that a decrease in LBP level by more than $280 \mathrm{ng} / \mathrm{ml}$ increases the probability of postsurgical complications in CRC patients (OR 12.0, 95\% Cl: 1.8-80.4) (Table 2). There was no difference in the incidence of complications between patients with or without ABO (30.8\% and $30.4 \%$ respectively).

Table 2. Distribution of patients based on changes in lipopolysaccharide-binding protein level on the 3rd day after surgery and the presence of systemic inflammatory response syndrome and complications

\begin{tabular}{|c|c|c|}
\hline & $\begin{array}{l}\text { Number of patients with a decrease in LBP level } \\
\text { by more than } 280 \mathrm{ng} / \mathrm{ml} \text { on the } 3^{\text {rd }} \text { day after surgery }\end{array}$ & $\begin{array}{l}\text { Number of patients with a decrease in LBP level by less } \\
\text { than } 280 \mathrm{ng} / \mathrm{ml} \text { or its increase on the } 3^{\text {rd }} \text { day after surgery }\end{array}$ \\
\hline SIRS & 5 & 8 \\
\hline no-SIRS & 2 & 21 \\
\hline Complications & 5 & 5 \\
\hline No complications & 2 & 24 \\
\hline
\end{tabular}

LBP - lipopolysaccharide-binding protein, SIRS - systemic inflammatory response syndrome 


\section{Discussion}

The aim of the study was to analyze the dynamics of the LBP level as a potential risk factor for the development of SIRS and infectious and inflammatory complications in CRC patients. CRC patients still have a high risk of complications in the postoperative period. In this study, infectious and inflammatory complications, including sepsis, occurred in 11 patients (30.6\%), sepsis in 3 patients (8.3\%), which are quite high rates.

The main cause of postoperative infectious and inflammatory complications in CRC patients is the violation of the intestinal barrier, which occurs at the site of the tumor growth, as the tumor causes dysplasia of the epithelium. In the case of $\mathrm{ABO}$ presence, some alterations additionally occur above the obstruction, where disturbances in the microcirculation of the intestinal wall, its ischemia and hypoxia take place. These disorders in the intestinal wall result in translocation of bacteria and their endotoxins into the systemic circulation and production of a large number of pro-inflammatory mediators. The inflammatory response increases, and oxidative stress occurs. These changes contribute to the death of enterocytes and disruption of intercellular tight junctions, which increases the intestinal wall permeability. Bacteria or their endotoxins penetrate the damaged intestinal mucous barrier and further enhance the immune response, which becomes systemic, and ultimately leads to SIRS and infectious and inflammatory complications, including sepsis [23].

Komen et al. [24] analyzed the LBP levels in drain fluid of the operated CRC patients during the first five postoperative days. The LBP levels were higher on days two, three and four. The authors found that an increase from the average initial value at the first postoperative day with one SD increased the risk of colorectal anastomotic leakage by 1.6 times. In Scheepers et al.'s study on patients undergoing laparoscopic or open transhiatal esophagectomy during the observation period, significantly higher plasma LBP levels were observed after laparoscopic surgery $(p=0.009)$. The scientists came to the conclusion that the persistently elevated abdominal pressure resulted in the loss of the intestinal barrier function, leading to BT [25]. In patients with $A B O$, abdominal pressure is also increased, so BT also occurs with $A B O$.

In research by Mierzchala et al., the LBP value was assessed in patients with sepsis and septic shock. The serum levels of LBP were significantly higher in the patients with SIRS, sepsis and septic shock, as compared with the levels in the healthy controls. Additionally, the LBP level was higher in non-survivors compared to survivors. High levels of LBP were present at admission and gradually decreased on the following days $[21,26,27]$. On average, the decrease in LBP level in the septic patients was $12.8 \mathrm{mg} / \mathrm{l}$ (95\% Cl: -22.4 to -3.2 ). A decrease in LBP level over time was observed in $71.3 \%$ of survivors and in $38.5 \%$ of non-survivors [27]. It should be noted that the LBP response appeared to exhibit a decreased magnitude in the septic patients [26].

In Opal's study, LBP levels were measured in patients with severe sepsis. The authors also found that the LBP values were elevated in the patients with sepsis compared with the normal control values. Nevertheless, the authors witnessed significantly worse outcomes in the patients with less highly elevated levels of LBP in contrast to the previous studies. The authors concluded that the patients with rapidly progressive sepsis could not adequately synthesize LBP, lacking time to adequately respond to some systemic microbial infection [28].

Previously, in patients with CRC, LBP has not been thoroughly studied in real-time mode in serum plasma, depending on the presence of $A B O$ upon admission or the occurrence of SIRS and infectious and inflammatory complications. This study showed that the pre-operative LBP level in the operated CRC patients was $879.8 \pm 221.8 \mathrm{ng} / \mathrm{ml}$ (IQR 749.3-1028.8) and $766.5 \pm 159.4 \mathrm{ng} / \mathrm{ml}$ (IQR 669.5$847.6)$ on the $3^{\text {rd }}$ day, which was a statistically significant decrease $(p=0.004)$.

In this study, the patients with $\mathrm{ABO}$ also had a statistically significant decrease in the LBP concentration ( $p=0.023$ ). In these patients, in addition to the changes in the intestinal wall due to obstruction and tumor, an increase in the intraabdominal pressure occurs, which increases BT. It can be assumed that the dynamic decrease in the LBP level might be due to the normalization of intraabdominal pressure, elimination of obstruction, and removal of the tumor itself, which all together caused BT.

In previous studies, a difference in the change of the LBP concentration in real-time mode has not been observed anywhere. For the first time ever, this study observed that the decrease in the LBP level by more than $280 \mathrm{ng} / \mathrm{ml}$ increased the probability of developing postoperative infectious and inflammatory complications in the operated CRC patients (OR 12.0, 95\% Cl:1.8-80.4). Moreover, the most frequent postoperative complication was an anastomotic leakage (6 patients; $16.7 \%$ ). A combination of several complications was observed in 5 patients, mostly anastomotic leakages and abdominal abscesses. Only 3 patients had sepsis (8.3\%). The LBP value before the surgery in the patients with complications ranged from 448.35 to $1308.2 \mathrm{ng} / \mathrm{ml}$, and from 503.6 to $1062.5 \mathrm{ng} / \mathrm{ml}$ on the $3^{\text {rd }}$ day, which showed the lowest levels in total in all the patients. Also, the group of patients with complications had the largest decrease in the LBP concentration (448.4 $\mathrm{ng} / \mathrm{ml}$ ). Moreover, such a decrease in the LBP level by more than $280 \mathrm{ng} / \mathrm{ml}$ increases the probability of SIRS (OR 6.6, 95\% Cl: 1.1-40.9).

As in the previous studies, the mean LBP level tended to decrease on the $3^{\text {rd }}$ day. Yet, significantly worse results (the presence of SIRS and complications) were observed in the patients with a lower LBP level on the $3^{\text {rd }}$ day and with a more significant decrease in its dynamics. This is at odds with the previous studies, except for Opal's study. The LBP may contribute to the protection and elimination of pathogenic bacteria and their endotoxins [29, 30]. According to the previous studies, the LBP level should increase with SIRS and occurrence of infectious and inflammatory complications. However, this study resulted in demonstrating that the patients with lower LBP levels on the $3^{\text {rd }}$ day after the surgery and with a bigger decrease in LBP level are more prone to developing SIRS and infectious and inflammatory complications. As mentioned above, 
the alterations in the intestinal wall in the CRC patients result in the translocation of bacteria and their endotoxins into the systemic circulation. One study found that the presence of low endotoxin (LPS) levels in the patients with chronic disease leads to a constant state of low-grade inflammation that prevents the normal healing process [31], which can explain the high rate of postoperative complications in the operated CRC patients. Also, a decrease in the LBP level in the operated CRC patients is possible due to immunodeficiency and inability to produce an appropriate immune response to infectious stimuli, which can lead to a poor prognosis (SIRS and infectious and inflammatory complications). Similar to the study of Citronberg [12], the present study observed that the association of LBP and CRC was not stronger in patients with a later stage.

This is a pilot study and hence it has some limitations. The statistical power of the study is limited (36 patients only). Nevertheless, to our best knowledge, this is the first study that assesses the dynamics of LBP levels in operated $C R C$ patients, depending on the presence of $A B O$ upon admission and the occurrence of postoperative infectious and inflammatory complications. Compared to most previous studies, a poor prognosis is observed in the patients with a large decrease in the LBP levels from baseline.

\section{Conclusions}

This study demonstrated that the LBP level in the operated CRC patients tends to decrease on the $3^{\text {rd }}$ day after the surgery. A bigger decrease in the LBP level increases the probability of SIRS and postoperative infectious and inflammatory complications. Therefore, further studies with larger numbers of patients are required.

\section{Acknowledgements}

This research is funded by the Science Committee of the Ministry of Education and Science of the Republic of Kazakhstan (Grant No. AP08956335).

The study was conducted in accordance with the Ethical Guidelines for Medical Research with Human Subjects as established by the Ministry of Health of the Republic of Kazakhstan and with the guidelines outlined in the Helsinki Declaration and its amendments. This study was approved by the Ethics Committee of the NJSC "Karaganda Medical University" (Protocol No. 6 with the assigned number No. 30). Informed consent was obtained from all participants of the study.

The authors declare no conflict of interests.

\section{References}

1. Siegel RL, Miller KD, Jemal A. Cancer statistics, 2019. CA: Cancer J Clin 2019; 69: 7-34.

2. Kam MH, Tang CL, Chan E, et al. Systematic review of intraoperative colonic irrigation vs manual decompression in obstructed left-sided colorectal emergencies. Int J Colorectal Dis 2009; 24: 1031-1037.

3. Catena F, de Simone B, Coccolini F, et al. Bowel obstruction: a narrative review for all physicians. World J Emerg Surg 2019; 14: 20.
4. Webster PJ, Aldoori J, Burke DA. Optimal management of malignant left-sided large bowel obstruction: do international guidelines agree? World J Emerg Surg 2019; 14: 23.

5. Sperry J, Cohen MJ. Acute obstruction. Surg Clin North Am 2014; 94: 77-96.

6. Vaishnavi C. Translocation of gut flora and its role in sepsis. Indian J Med Microbiol 2013; 31: 334-342.

7. Zweigner J, Schumann RR, Weber JR. The role of lipopolescchride-binding protein in modulating the innate immune response. Microb Infect 2006; 8: 946-952.

8. Heumann D, Lauener R, Ryffel B. The dual role of LBP and CD14 in response to Gram-negative bacteria or Gram-negative compounds. J Endotoxin Res 2003; 9: 381-384.

9. Ryu JK, Kim SJ, Rah SH, et al. Reconstruction of LPS transfer cascade reveals structural determinants within LBP, CD14, and TLR4. MD2 for efficient LPS recognition and transfer. Immunity 2017; 46: 38-50.

10. Leventhal JS, Schröppel B. Toll-like receptors in transplantation: sensing and reacting to injury. Kidney Int 2012; 81: 826-832.

11. Chen R, Luo F-K, Wang Y-L, et al. LBP and CD14 polymorphisms correlate with increased colorectal carcinoma risk in Han Chinese. World J Gastroenterol 2011; 17: 2326-2331.

12. Citronberg JS, Wilkens LR, Marchand LL, et al. Plasma lipopolysaccharide-binding protein and colorectal cancer risk: a nested case-control study in the multiethnic cohort. Cancer Causes Control 2018; 29: 115-123.

13. Cybulska-Stopa B, Ługowska I, Wiśniowski R, et al. Overweight is associated with better prognosis in metastatic colorectal cancer patients treated with bevacizumab plus FOLFOX chemotherapy. Contemp Oncol (Pozn) 2020; 24: 34-41.

14. Akhmaltdinov L, Sirota V, Babenko D, et al. Proinflammatory cytokines and colorectal cancer - the impact of the stage. Contemp Oncol (Pozn) 2020; 24: 207-210.

15. Mu Q, Kirby J, Reilly CM, Luo XM. Leaky gut as a danger signal for autoimmune diseases. Front Immunol 2017; 8: 598.

16. Cesaro C, Tiso A, Del Prete A, et al. Gut microbiota and probiotics in chronic liver diseases. Dig Liver Dis 2011; 43: 431-438.

17. Tuomi K, Logomarsino JV. Bacterial lipopolysaccharide, lipopolysaccharide- binding protein, and other inflammatory markers in obesity and after bariatric surgery. Metab Syndr Relat Disord 2016; 14: 279-288.

18. Albillos A, de-la-Hera A, Alvarez-Mon M. Serum lipopolysaccharide-binding protein prediction of severe bacterial infection in cirrhotic patients with ascites. Lancet 2004; 363: 1608-1610.

19. Gaini S, Koldkajer OG, Pedersen SS. Procalcitonin, lipopolysaccharide-binding protein, interleukin-6 and C-reactive protein in community-acquired infections and sepsis: a prospective study. Crit Care 2006; 10: R53.

20. Kell DB, Pretorius E. On the translocation of bacteria and their lipopolysaccharides between blood and peripheral locations in chronic, inflammatory diseases: the central roles of LPS and LPS-induced cell death. Integr Biol 2015; 7: 1339-1377.

21. Mierzchala M, Krzystek-Korpacka M, Gamian A, Durek G. Quantitative indices of dynamics in concentrations of lipopolysaccharide-binding protein (LBP) as prognostic factors in severe sepsis/ septic shock patients - comparison with CRP and procalcitonin. Clin Biochem 2011; 44: 357-363.

22. Whitehead AL, Julious SA, Cooper CL, Campbell MJ. Estimating the sample size for a pilot randomised trial to minimise the overall trial sample size for the external pilot and main trial for a continuous outcome variable. Stat Methods Med Res 2015; 25: 1057-1073.

23. Deitch EA. Bacterial translocation or lymphatic drainage of toxic products from the gut: what is important in human beings? Surgery 2002; 131: 241-244.

24. Komen N, Slieker J, Willemsen P, et al. Acute phase proteins in drain fluid: a new screening tool for colorectal anastomotic leakage? The APPEAL study: analysis of parameters predictive for evident anastomotic leakage. Am J Surg 2014; 208: 317.

25. Scheepers JG, Sietses C, Bos DG, et al. Immunological consequences of laparoscopic versus open transhiatal resection for malignancies of the distal esophagus and gastroesophageal junction. Dig Surg 2008; 25: 140-147. 
26. Prucha M, Herold I, Zazula R, et al. Significance of lipopolysaccharide-binding protein (an acute phase protein) in monitoring critically ill patients. Crit Care 2003; 7: 154-159.

27. Villar J, Perez-Mendez L, Espinosa E, et al. Serum lipopolysaccharide binding protein levels predict severity of lung injury and mortality in patients with severe sepsis. PLoS One 2009; 4: e6818.

28. Opal SM, Scannon PJ, Vincent J-L, et al. Relationship between plas ma levels of lipopolysaccharide (LPS) and LPS-binding protein in patients with severe sepsis and septic shock. J Infect Dis 1999; 180: 1584-1589.

29. Lamping N, Dettmer R, Schroder NWJ, et al. LPS-binding protein protects mice from septic shock caused by LPS or Gram-negative bacteria. J Clin Invest 1998; 101: 2065-2071.

30.Zweigner J. High concentrations of lipopolysaccharide-binding protein in serum of patients with severe sepsis or septic shock inhibit the lipopolysaccharide response in human monocytes. Blood 2001; 98: 3800-3808

31. Morris MC, Gilliam EA, Li L. Innate immune programing by endotoxin and its pathological consequences. Front Immunol 2015; 5: 680 .

\section{Address for correspondence}

\section{Alina Ogizbayeva}

PhD student, Department of Surgical Diseases

NJSC “Karaganda Medical University"

40 Gogol str., Karaganda, Kazakhstan

e-mail: eleusizova.a@kgmu.kz

Submitted: 30.06 .2021

Accepted: 19.09 .2021 